\title{
Cognitive retardation in a patient with preservation of psychomotor speed
}

\author{
J.R. Willison and E.K. Warrington \\ National Hospital, Queen Square, London WC1N 3BG, UK
}

Correspondence to: E.K. Warrington at above address

\begin{abstract}
We describe a patient (R.S.) who after a bout of probable TB exhibited an unusual pattern of response retardation, although given time he was able to score at a satisfactory level. He was strikingly slow to initiate speaking and to carry out higher level cognitive tasks, at a time when he could complete a variety of psychomotor activities at normal speed. He showed many similarities with patients previously described as having subcortical dementia. The selective preservation of psychomotor responding in the context of his gross bradyphrenia, however, was unexpected.
\end{abstract}

Keywords: Bradyphrenia - Psychomotor abilities - Subcortical dementia

\section{INTRODUCTION}

Subcortical dementia (SCD) refers to a clinical syndrome in which mental slowing and disturbances of attention, recall and judgement occur in conjunction with subcortical lesions. The aphasic, agnosic and apraxic syndromes which are traditionally associated with cortical dementing conditions are absent from SCD (Albert et al., 1974). One of the chief behavioural features used to separate the two types of dementia is psychomotor slowing, which is said to be generally preserved in cortical dementia and invariably present in SCD (Cummings, 1986). The patients described by Albert and his colleagues showed a dramatic discontinuity between their eventual success at answering questions and their slow speed of doing so.

The patient we describe here was reminiscent of the patients who formed the basis of the original description of SCD but at the same time displayed a pattern of selective retardation which, to our knowledge, has not been recorded before. We were able to monitor his progress closely over a 6-week period during the early stages of his recovery.

\section{PATIENT HISTORY}

R.S. was born in Malawi in 1950, and spoke English as his first language. He moved to England to study and settled in this country upon getting married. After failing in his first efforts to qualify in law he changed careers and became a magazine editor. At the age of 33 he developed the illness which led to his hospitalisation. It began with fever and malaise which varied in intensity but gradually worsened. In 2 months from onset he had lost weight and developed signs of severe meningism as well as hepatitis and pan- creatitis. Tuberculosis was suspected but diagnostic tests remained negative. He was admitted to the National Hospital in coma where in view of his serious condition anti-TB therapy was started. From that time his condition stabilised and he began a slow improvement.

His first EEGs were abnornal with intermittent episodic activity characteristic of brain-stem dysfunction. Initial CT scanning showed changes in the frontal lobes compatible with frontal horn compression. A month later these appearances had resolved but small low density lesions had become visible in both internal capsules, with patchy enhancement of the caudate nuclei after contrast. An EEG at this time showed improvement from the records obtained initially. VEPs recorded as soon as the patient was able to cooperate with the procedures were normal.

\section{CLINICAL OBSERVATIONS}

As R.S.'s medical condition improved it became apparent that his mental state was abnormal. He appeared aware of his surroundings but he was quiet, spoke only infrequently, and lacked spontaneity apart from automatic behaviours such as yawning and scratching. One medical observer seeing him at this time described him as reminiscent of patients with encephalitis lethargica. Nursing staff noted that he preferred to write answers to their questions rather than speak them.

He was first seen for psychological assessment 6 weeks after the start of TB therapy, in September 1984. He had striking diminution of his language use but when he spoke his words were clear and correctly articulated. He knew where he was, the time of year and was within a day or two

Behavioural Neurology . Vol 5 . 1992

113 
TABLE I. Analysis of number of words in each spoken and written response in week 1 (in conversation) in weeks 3 and 6 (on the vocabulary test)

\begin{tabular}{lccc}
\hline & Week 1 & Week 3 & Week 6 \\
\hline Spoken & $\begin{array}{c}4.1 \\
(n=10)\end{array}$ & $\begin{array}{c}1.5 \\
(n=20)\end{array}$ & $\begin{array}{c}2.0 \\
(n=30)\end{array}$ \\
Written & 9.5 & 2.8 & 1.8 \\
& $(n=11)$ & $(n=27)$ & $(n=29)$ \\
\hline
\end{tabular}

of knowing the date. He could read and write normally, except that his handwriting was reduced in size. He was not apraxic on tests of copying sequences of hand movements. He was especially slow to initiate speaking; for example, naming 20 pictures of common objects took 15 min. He did not appear to be distracted or inattentive during this task. Rather, each response though accurate was inordinately slow.

Conversations held with him in these early interviews were fragmented and his comprehension was not entirely reliable. An example was the following:

Q: What jobs have you had?

R.S.: (after long delay) I drove a van.

Q: What other jobs have you had?

R.S.: (further delay) It was the only time I drove a van. There was little evidence of any primary depression of his mood at this time. In answer to one query when he was physically still very weak, he wrote that he wanted to discharge himself from hospital. He experienced other people as "rushing about" rather than himself as being very slow.

His reading vocabulary and naming skills were well preserved even at the earliest stage of our assessment. He scored 96/100 on the Schonell Graded Word Reading Test, during the first week of testing. He retrieved an average number of object names on the Graded Naming Test $(15 / 30)$ and was able to identify some of the remainder in writing. For example, he wrote that "sextant" was "an instrument used at sea for adjusting the position of ships." His forwards digit repetition span was 7 and he solved at a very slow pace five Matrices problems, indeed the test was unfinished because of his slowness of responding (from Raven's Advanced Set 1).

By examining R.S.'s spontaneous verbal responses from the first four interviews we found that his written productions on average contained more words than his spoken ones. This same pattern of responding, where written productions tended to be twice as wordy as spoken ones, was also observed on Wechsler Vocabulary definitions given to him 2 weeks later. By the end of our period of intensive observations (in early November 1984) this advantage of written over spoken definitions had completely disappeared (Table I).

A short WAIS assessment consisting of four verbal and three non-verbal subtests was completed by the end of the
TABLE II. WAIS verbal and performance IQ scores (pro-rated) with and without time limits

\begin{tabular}{llccc}
\hline & & Oct 83 & Dec 83 & Apr 84 \\
\hline Verbal & Timed & 94 & 110 & 123 \\
IQ & Untimed & 98 & 110 & 123 \\
Performance & Timed & 74 & - & 101 \\
IQ & Untimed & 91 & - & 103 \\
\hline
\end{tabular}

second week (see Table II). His performance was slow enough to be affected by the time limits on items from the Arithmetic, Picture Completion, Block Design and Picture Arrangement tests. Under normal conditions these time limits do not affect outcome significantly. In the case of R.S. his overall IQ scores improved the more time he was given, underlining how relatively slow he was to respond to these types of intellectual problems. He was particularly impressive with the Picture Arrangement items, solving $7 / 8$ correctly (three of which were over the time limit). The scores from calculating pro-rated WAIS IQs with and without the operation of time limits are given in Table II.

Further assessments with the WAIS over ensuing months demonstrated that cognitive improvement continued to occur for some time. There was no significant gain at these follow-up assessments from ignoring standard time limits (see Table II). The quality of his verbal responding at 6 months follow-up (April 1984) was for the most part excellent, with only occasional hesitancies and mild word-finding difficulties. His non-verbal abilities, while certainly improved at 6 months, were judged to be below their premorbid level in terms of quality and flexibility of thinking. He was living at home again by this time. He reported being lacking in energy and having difficulty with picking up domestic routines and organising his activities.

\section{NEUROPSYCHOLOGICAL INVESTIGATIONS}

R.S. was studied intensively over a 6-week period (late September-mid-November 1983). Neuropsychological investigations were carried out under three headings: psychomotor speed; speed of naming; problem-solving ability.

\section{Psychomotor speed}

By "psychomotor" we mean the performance of simple repetitive tasks within a time span of about $1 \mathrm{~min}$. Such tasks are more extended than Reaction Time measures but not designed to assess persistence or vigilance. We selected a number of tests involving verbal as well as visuomotor responses (Willison, 1988). They were given under the instruction to work as quickly as possible.

Six psychomotor tests were administered on three occasions, at weeks 1,3 and 6 of the assessment period. 
TABLE III. Psychomotor speed test results in seconds

\begin{tabular}{lrrrrrrr}
\hline & \multicolumn{3}{c}{ Week } & & \multicolumn{2}{c}{ Controls $(n=80)$} \\
\cline { 2 - 3 } \cline { 7 - 7 } & 1 & 3 & 6 & & $25 \%$ & $50 \%$ \\
\hline 1. Recite months & 4 & 4 & 4 & & 4 & 3 \\
2. Count back & 15 & 15 & 14 & & 17 & 14 \\
3. Read numbers & 19 & 19 & 16 & & 15 & 13 \\
4. Copy digits & 74 & 60 & 44 & & 44 & 35 \\
5. Count letter & 25 & 20 & 13 & & 18 & 14 \\
6. Cancel letter & 36 & 32 & 23 & & 21 & 18 \\
\hline
\end{tabular}

Three of the tasks were verbal (tasks 1-3) and three visuomotor (tasks 4-6). They are briefly described as follows (all results are time scores in seconds):

1. Reciting months: the subject is asked to recite the months of the year forwards and the time taken is recorded; 2. Counting backwards: the subject is instructed to count backwards from 30 to 1; 3. Reading numbers: 24 two-digit numbers are read aloud by the subject; 4 . Digit copying: 60 digits arranged randomly in six rows are copied by the subject; 5. Letter counting: the subject counts the total occurrences of a target letter (B) on a sheet of five random letters (A, B, C, D, E); 6. Letter cancellation: the subject is instructed to cancel all the occurrences of a target letter (B) on the same sheet of random letters.

R.S.'s times in seconds on each of the six psychomotor tests are given in Table III. For comparison, we include normative data for the 25th and 50th percentiles from 80 adult controls aged between 20 and 44 years (Willison, 1988). R.S. showed remarkably intact results on some of these tests from the start of our assessment and by week 6 he was within the average range on all of them (see Table III).

These data show that R.S. was able to perform at least one kind of automatic speech at normal speed and to count backwards, even at a time when his conversational speech was almost absent (week 1, September 1983). His results on the three visuo-motor tests (Nos. 4-6) were slower to improve. By the end of week 6 , however, he was close to average at Digit Copying and the two kinds of visual search task used, viz. Count Letter and Cancel Letter. This was at a time (November 1983) when he was still unusually slow to express himself spontaneously, whether in spoken or written form. The lack of inertia on the psychomotor tasks was particularly noticeable, in the sense of there being a negligible delay between our presenting the instructions and his starting the task.

\section{Speed of naming}

The Graded Naming Test (McKenna and Warrington, 1983) was given to R.S. on two occasions in week 4 of testing in both written and spoken forms. The test occasions were separated by 2 days, on the first of which he reported that he felt "sleepy" and on the second he
TABLE IV. Variation in naming speed and naming ability in each spoken and written response

\begin{tabular}{ccccc}
\hline & 18.10 .83 & 20.10 .83 & Controls $(n=46)$ \\
\hline Spoken No. correct & 20 & 22 & 21.7 \\
Av. latency & $9.8^{\prime \prime}$ & $2.0^{\prime \prime}$ & $2.2^{\prime \prime}$ \\
Range & $1-60 "$ & $1-7^{\prime \prime}$ & S.D. 0.7 \\
Written No.correct & 20 & 21 & \\
Av. latency & $12.8^{\prime \prime}$ & $2.3^{\prime \prime}$ & \\
Range & $1-40 "$ & $1-15^{\prime \prime}$ & \\
\hline
\end{tabular}

appeared more alert. The delay or latency before he uttered or began to write a name was recorded for each item. The number of items he named correctly, his average response latencies for the correct responses and their range are given in Table IV.

Data are available for comparison from 46 normal controls who completed the spoken condition of this task (Callanan-Kelsey, 1990). Their mean score, and the mean and standard deviation of their response latencies are also given in Table IV.

These results show that on the first occasion R.S. was unusually slow to respond while succeeding in naming an average number of items. This was true in both spoken and written modalities. When tested 2 days later his mean response latency had improved to a normal level, though five responses (two spoken and three written) could still be categorised as abnormally slow (more than $2 \mathrm{~s}$ ).

\section{Problem-solving ability}

From early on in our sessions with R.S. we noted that, despite his slow response times, he was capable of a satisfactory level of problem-solving. In order to measure this objectively, in week 3 he was tested on a set of 18 Raven's Matrices problems (reduced from the 60 Standard Progressive Matrices) and encouraged to solve them as quickly as he could. He gained a low average score, taking $27 \mathrm{~min}$ to do so. This was compared with the performance of 12 normal adults who obtained similar low average scores on these items (Willison, unpublished data). Their mean solution time was $6.5 \mathrm{~min}$ with a range from 4 to 11 min. Thus, again on a cognitive task R.S. was found to be slower by several orders of magnitude at a time when his responses on a number of psychomotor tests were in the normal range (Table III).

\section{DISCUSSION}

Our patient R.S. presented with a mental state which, while closely fitting Albert et al.'s description of subcortical dementia, was in some respects novel. There was a very great discrepancy between the level of his cognitive skills, which were relatively intact from an early stage in his recovery, and his speed of responding, which was 
unusually slow. Despite the difficulties posed by his severe bradyphrenia we were able to demonstrate that his psychomotor functioning on a number of tests was surprisingly quick at a time when like Albert's patients he was very slow to answer questions on personal information and general knowledge. We further observed that his slowness affected a wide variety of cognitive functions including naming, the performance of Wechsler Intelligence Scale items and solving Raven's Matrices problems.

There were broad consistencies in his responding from one occasion of testing to the next but also fluctuations in his latencies and in the number of slow responses. We could not predict from item difficulty or from previous experience of his responding on a task when he might answer very slowly. Whatever his condition, however, he was always quick to make a start on psychomotor tasks when instructed to do so. This discontinuity between psychomotor and cognitive functioning was unexpected because the common descriptions of sub-cortical dementia stress psychomotor slowing as a cardinal feature. Our patient appeared to have a selective bradyphrenia.

Arousal difficulties have been implicated in the aetiology of SCD as has the related deficit of loss of cognitive activation (Laplane et al., 1984). A simple hypothesis of general loss of arousal could not explain our patient's selective pattern of bradyphrenia. His tendency in an early part of his recovery to write rather than to speak points to a highly selective problem with response initiation or activation. His readiness to carry out psychomotor tasks and to undertake "automatic" behaviours (such as scratching or drinking tea) was also evidence against a general loss of arousal.

Our aim in presenting this case is not to contribute to the debate surrounding subcortical dementia (Chui, 1989) but rather to draw attention to the fact that cognitive slowing can be highly task-specific. The precise anatomical correlates of the behaviour pattern we observed could not in this case be resolved, though as with other SCD patients lesions in the frontal and basal ganglia regions were chiefly implicated. Further studies comparing psychomotor speed with cognitive speed in patients with well localised, circumscribed lesions will be necessary in order to understand the aetiology of such selective bradyphrenia deficits.

\section{Acknowledgements}

We wish to thank Professor J. Marshall for permission to investigate R.S., a patient under his care, and to report our findings.

\section{References}

Albert ML, Feldman RG and Willis AL (1974) The "subcortical dementia" of progressive supranuclear palsy. Journal of Neurology, Neurosurgery and Psychiatry, 37, 121-130.

Callanan-Kelsey MM (1990) Cognitive impairment in multiple sclerosis: clinical and nuclear magnetic resonance imaging correlates. PhD thesis, London University.

Chui HC (1989) A review emphasising clinicopathologic correlation and brain behaviour relationships. Archives of Neurology, 46, 806-814.

Cummings JL (1986) Subcortical dementia-neuropsychology, neuropsychiatry and pathophysiology. British Journal of Psychiatry, 149, 682-697.

Laplane D, Baulac M, Widlocher D and Dubois B (1984) Pure psychic akinesia with bilateral lesions of basal ganglia. Journal of Neurology, Neurosurgery and P sychiatry, 47, 377-385.

McKenna P and Warrington EK (1983) Graded Naming Test. NFER-Nelson, Windsor, UK.

Willison JR (1988) Neuropsychological investigations of a set of mental speed tests. PhD thesis, London University. 


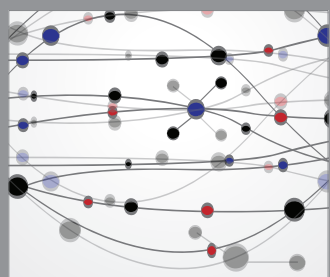

The Scientific World Journal
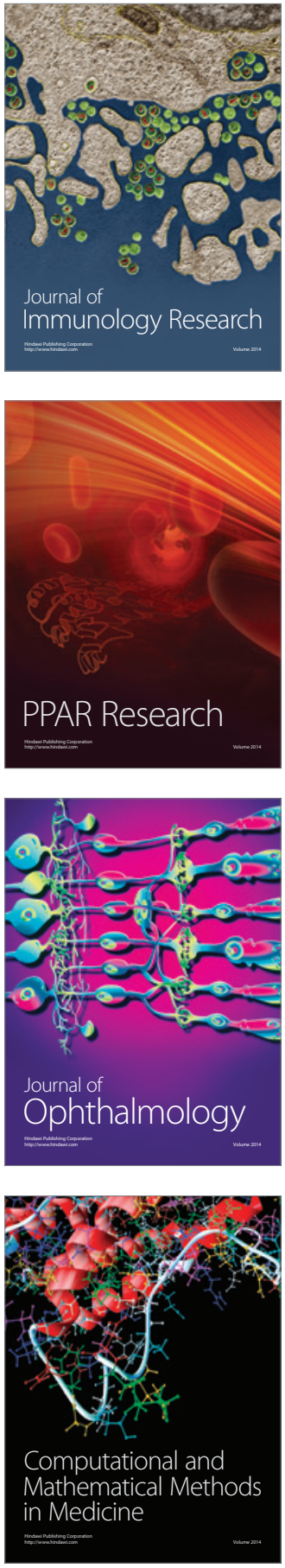

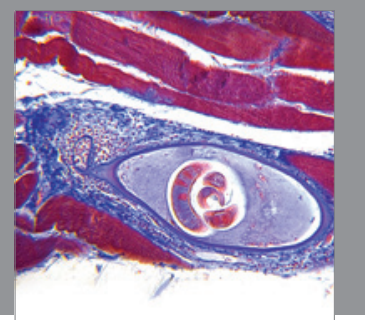

Gastroenterology

Research and Practice
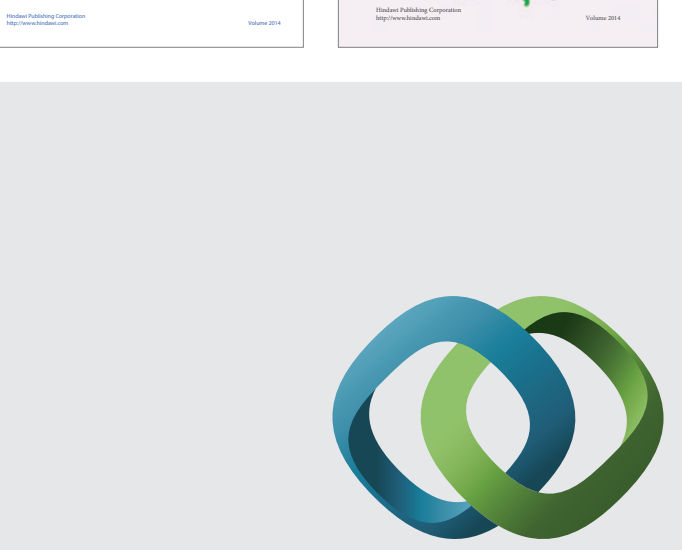

\section{Hindawi}

Submit your manuscripts at

http://www.hindawi.com
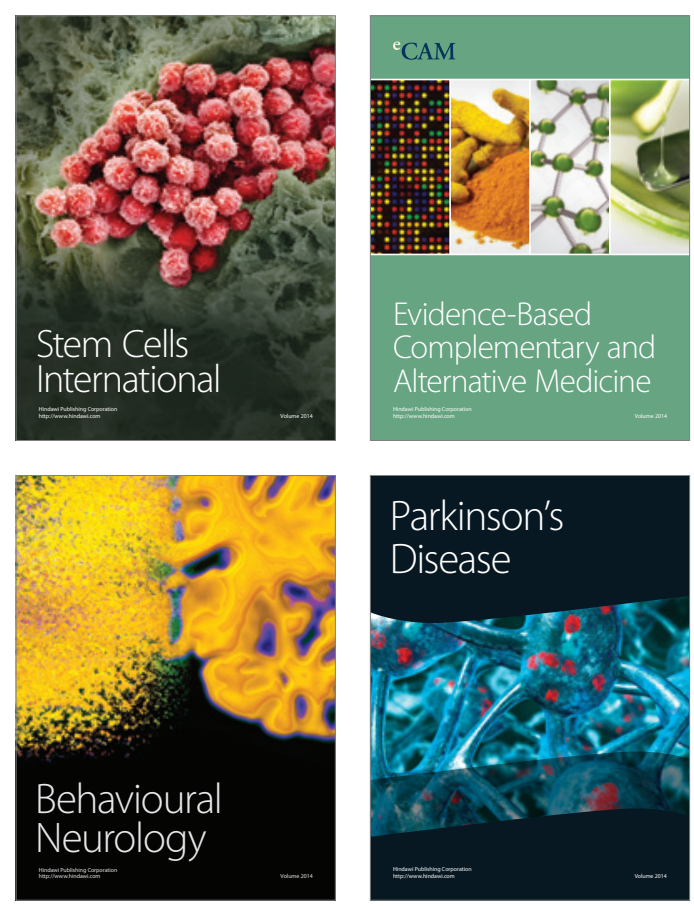

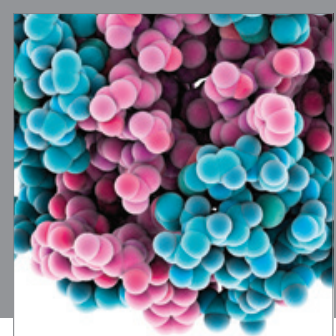

Journal of
Diabetes Research

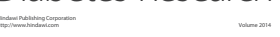

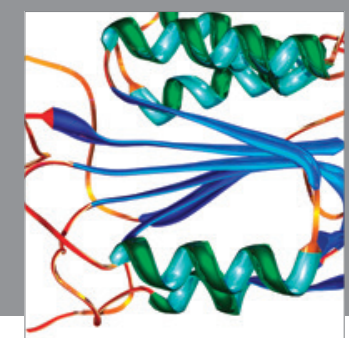

Disease Markers
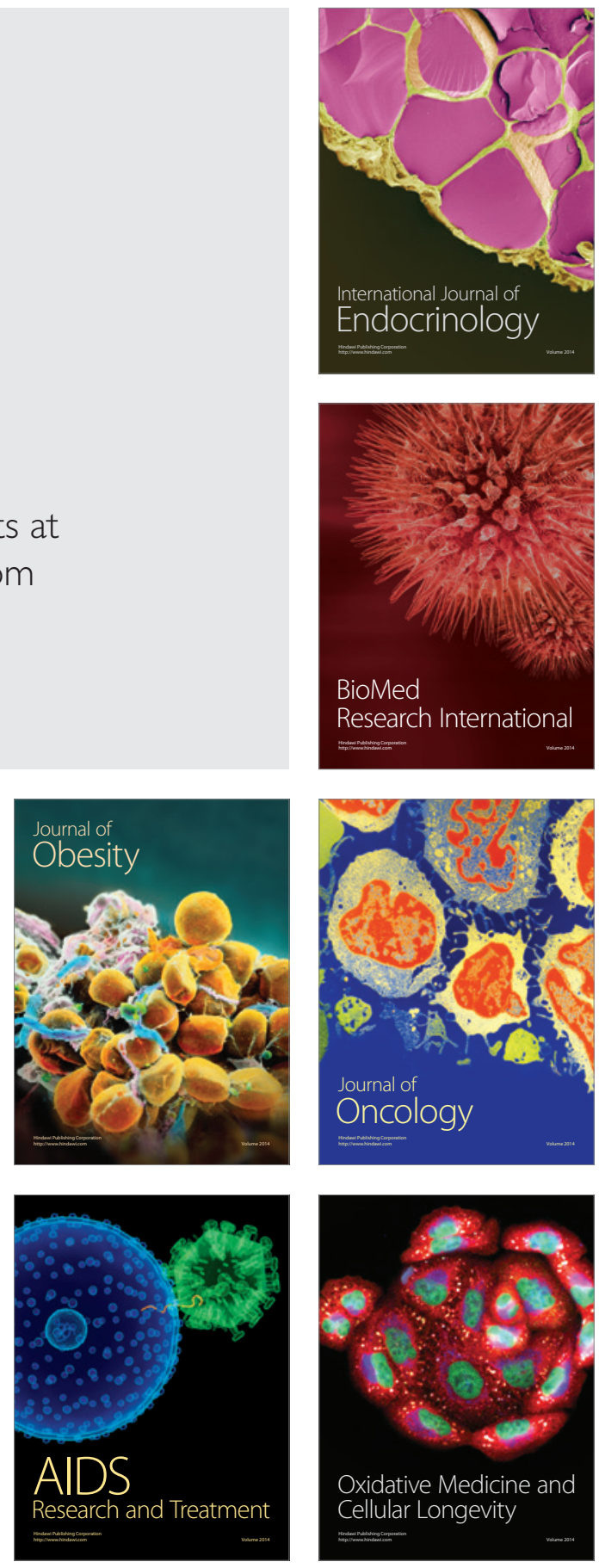